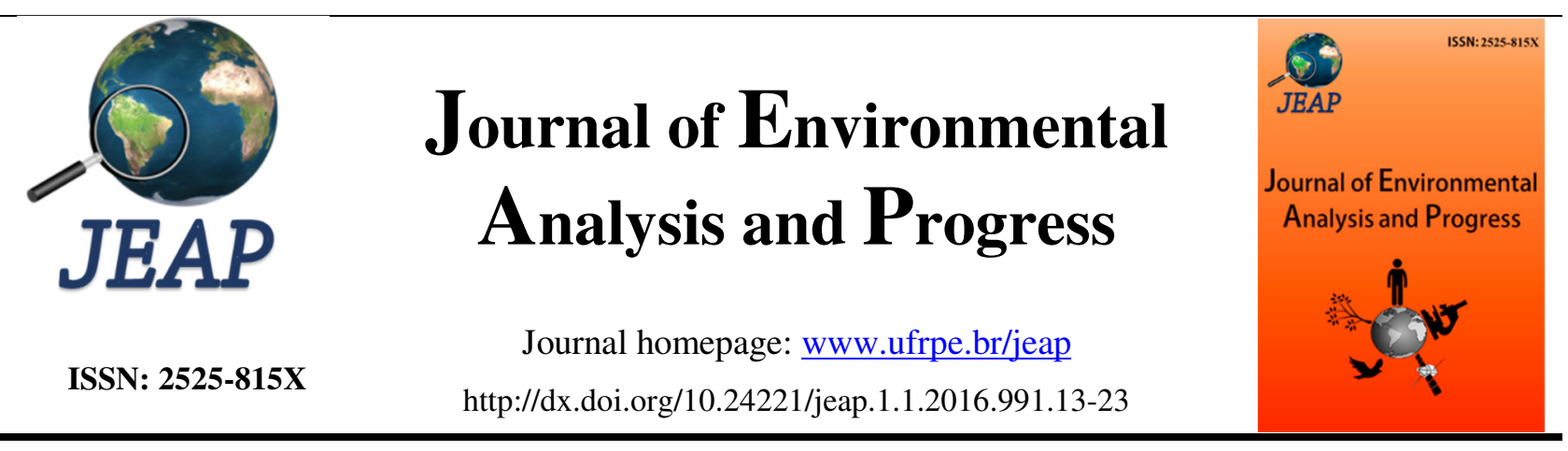

\title{
O uso da natureza no processo de construção do urbano: quem tem tido direito aos ventos marítimos em Recife-Brasil?
}

\section{Nature's use in the process of urban construction: who has been entitled to maritime winds in Recife-Brazil?}

\author{
Cláudio Jorge Moura de Castilho ${ }^{\mathrm{a}}$, Arthur Felipe de Melo Teixeira ${ }^{\mathrm{b}}$ \\ a Professor da Universidade Federal de Pernambuco-UFPE, Coordenador do Grupo de Pesquisa Movimentos Sociais e \\ Espaço Urbano, Av. Acadêmico Hélio Ramos, s/n, Cidade Universitária. CEP: 50740-530. Recife-PE, Brasil. E-mail: \\ claudiocastilho44@gmail.com. \\ b Aluno do Curso de Bacharelado em Geografia da UFPE e bolsista de Iniciação Científica da Facepe. E-mail: \\ ameloteixeira23@gmail.com.
}

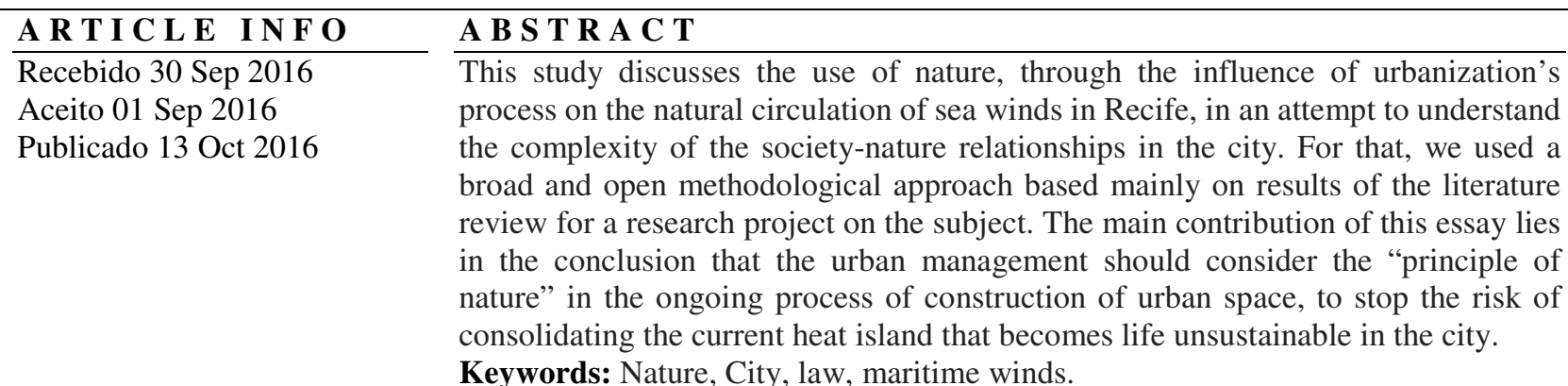

\section{R E S U M O}

Discute-se o uso da natureza, através da influência do processo de urbanização na
circulação natural dos ventos marítimos em Recife, na tentativa de entender a
complexidade das relações sociedade-natureza na cidade. Para isso, utilizou-se de
uma abordagem metodológica ampla e aberta com base em resultados da revisão
bibliográfica executada na construção do projeto de pesquisa sobre o tema. A
principal contribuição deste ensaio reside na conclusão de que a gestão urbana deve
considerar o "princípio de natureza" no processo contínuo de construção do espaço
urbano, senão correr-se-á o risco de consolidar a atual situação de ilha de calor que
poderá tornar a vida na cidade insustentável.
Palavras-Chave: Natureza, cidade, direito, ventos marítimos.

\section{Introdução}

Dando continuidade a uma linha de estudos, pesquisas e publicações acerca do tema da concepção e prática da natureza no processo de produção do espaço urbano, no âmbito do Grupo de Pesquisa Movimentos Sociais e Espaço Urbano (MSEU) da Universidade Federal de Pernambuco (UFPE), pretende-se, neste ensaio, dar ênfase à questão do uso dos ventos marítimos no processo de construção do espaço urbano em Recife.
Trata-se de uma questão colocada há décadas pela geografia urbana local, mas que ainda não foi contemplada como se deve nos processos atuais de gestão urbana. Recolocamos, assim, esta questão a fím de retomar uma reflexão crucial para entendermos o uso da natureza, por exemplo, em ações urbanísticas atuais. Nesta discussão da relevância do uso dos ventos marítimos no processo de construção do espaço urbano, indagarse-á sobre quem de fato tem conseguido garantir seu direito a estar, pelo menos, próximo de tal 
elemento da natureza no curso da história urbana da cidade de Recife.

Até o presente momento, a maior parte dos estudos realizados no MSEU-UFPE tem-se, portanto, debruçado sobre o uso da água e da vegetação em ações urbanísticas de caráter higienista e gentrificador ocorridas recentemente, tendo já acumulado informações interessantes para o que ocorre em Recife.

O destaque que passamos agora a dar aos ventos reside no fato da busca do entendimento da complexidade no que tange ao uso da natureza nas práticas urbanísticas inerentes ao processo de construção do espaço urbano, juntando os fragmentos existentes na perspectiva de, através de um esforço interdisciplinar, compor a totalidade complexa visando ao entendimento do urbano. Esta é, portanto, uma condição sine qua non para ações mais próximas do que almejamos em termos da sustentabilidade na cidade.

Com efeito, a relevância de estar localizado no caminho dos ventos marítimos, como atenuador da "acentuada tropicalidade do clima do Recife", havia sido destacada ao final dos anos 1970, no âmbito de trabalhos sobre o processo de produção do espaço urbano in situ. Como fatores atenuadores dessa acentuada tropicalidade, além da existência das árvores e das águas, deve-se considerar, ao mesmo tempo,

[...] o soprar das brisas do quadrante leste. Seus efeitos são ajudados pela não existência na RM [Região
Metropolitana] ou em torno dela de uma barragem orográfica suficientemente enérgica para interceptar ou perturbar a livre circulação atmosférica. A planície costeira, inclusive no bolsão do curso do rio Capibaribe [...], é varrida pelos ventos do mar sem maiores obstáculos que, mesmo à retaguarda, os pudessem perturbar. Até no espaço urbano central, onde a massa de edifícios já possui dimensões capazes de produzir efeitos locais de ventilação interceptada, existem sempre áreas de circulação atmosférica livre, representadas por algumas avenidas e principalmente pelos largos corredores ocupados pelas águas e atravessados pelas pontes (Melo, 1978, p. 39).

Em sendo assim, a densidade em termos de espaço construído na cidade já, naquele período de final dos anos 1970, rebatia no agravamento em termos de diferenciação de zonas urbanas em função da maior ou menor presença de calor. Daí por que, ainda para este mesmo autor, necessitarse-ia refletir sobre a lógica de construção urbana calcada na alta densificação de prédios de apartamentos à beira mar e, hoje, à beira rio, a qual foi responsável pelo preenchimento de áreas costeiras da planície flúvio-marinha no curso da história urbana do Recife (Figura 1).

Figura 1. Recife: sítio urbano original. Fonte: Castro (1964).

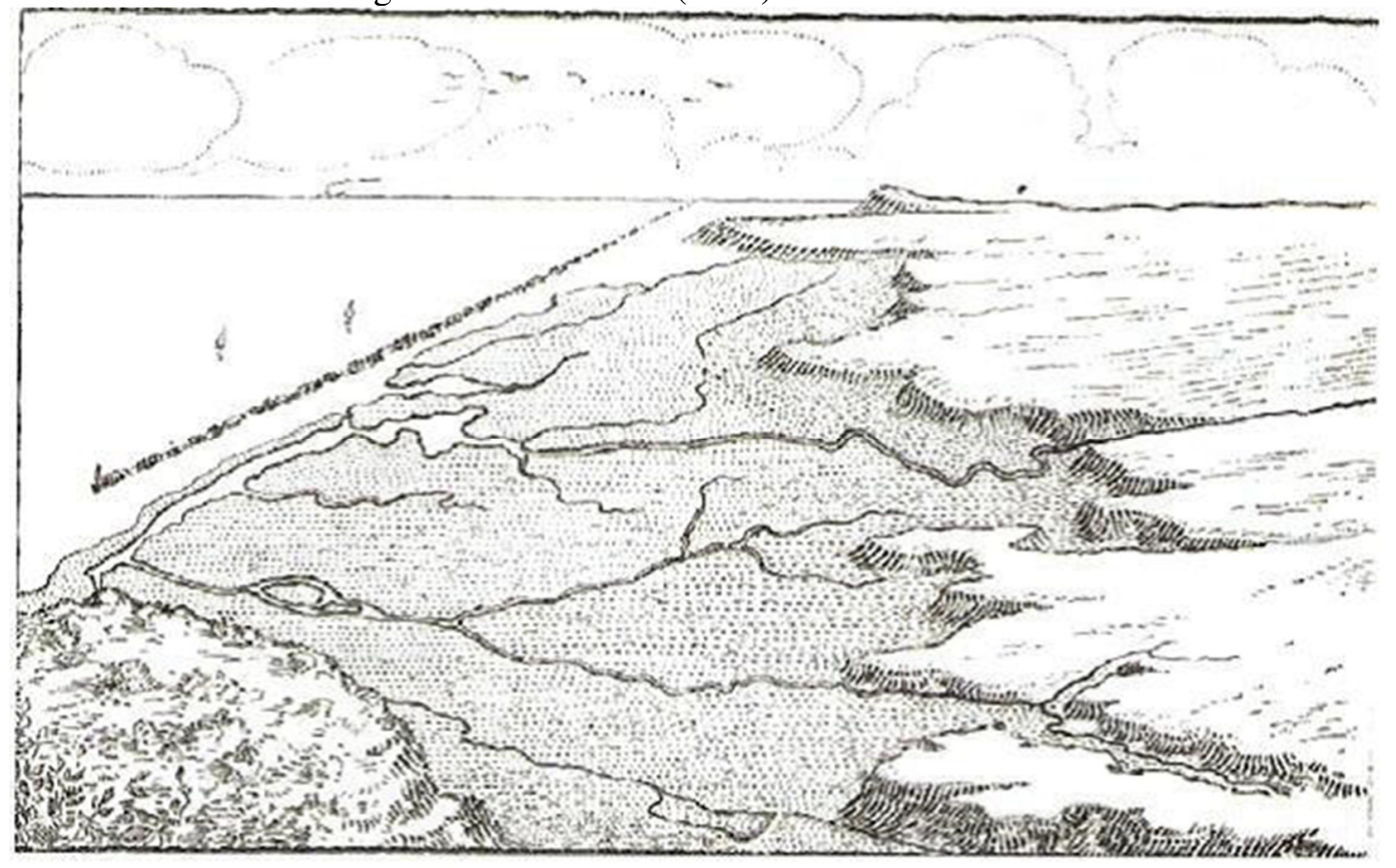

De acordo com a Figura 1, vê-se que a planície fluvio-marinha do Recife, cuja origem se acha numa baía que foi entulhada por sedimentos procedentes de processos de regressão marinha e 
dos cursos d'água nela existentes (Lins, 1982) foi, portanto, a base física sobre a qual a cidade foi construída no curso da sua história urbana. Espaço que, posteriormente, foi preenchido, também, por fixos e fluxos atinentes à urbanização, influindo na circulação dos ventos.

Percebia-se, então, a tendência que se foi consolidando, até os dias atuais, em termos de construção do espaço no tempo da história urbana local; o que, por sua vez, tem contribuído para a privatização do uso dos ventos marítimos, garantindo-os como direito apenas para quem pode pagar para morar nos prédios de apartamentos localizados justamente diante de áreas verdes, cursos d'água e dos ventos marítimos, negando este direito às classes sociais de mais baixo poder aquisitivo que moram em palafitas e favelas.

Em sendo assim, parcelas mais pobres da sociedade recifense, como em outros lugares do país e do mundo, têm sido afastadas das áreas que se valorizam pela dinâmica do mercado imobiliário, passando a instalarem-se - através das suas palafitas ou favelas - em outras áreas situadas às margens de rios e lagoas com a finalidade de continuarem próximas dos principais lugares do mercado - "informal" - de trabalho urbano, quando não são removidos para Conjuntos Habitacionais construídos pelo Estado. Mas que, ao mesmo tempo, beneficiaram-se da proximidade em termos da amenidade também dos ventos que circulam pelas calhas de tais superfícies líquidas, muito embora não se tenha tido consciência da busca, em princípio, por tal proximidade.

Dando continuidade à concretização dos imperativos da lógica técnico-instrumental capitalista neoliberal de construção do espaço urbano, os pobres também das áreas situadas em torno das águas fluviais e lacustres são removidos pelas ações urbanísticas que, calcadas na referida lógica, possuem como principal interesse a gentrificação desses territórios.

Eu proponho falar de gentrificação quando estamos em presença de um processo de produção de um espaço sofisticado e homogêneo a partir de um espaço urbano originalmente degradado (seja ele habitado ou não), o qual, desde então, apresenta transformações no seu aspecto exterior pela renovação das edificações existentes (conservando ou transformando a função original dos edifícios) ou pela construção de novos edifícios, e que se assenta sobre uma mobilidade residencial que ocorre pela instalação de uma nova população, e, se for o caso, pela partida da população previamente existente, mais ou menos forçada por diferentes tipos de pressão (Criekingen, 2006, p. 99-100).
Processo que vem acontecendo em várias cidades do mundo, hoje reforçado pela ideia de retorno à natureza, isto é, usando a natureza, preponderantemente, como recurso de valorização capitalista dos espaços urbanos que se reorganizam na perspectiva da urbanização reforçadora da produção contínua de valores financeiros (Castilho, 2014). Além do uso da proximidade com relação à água e ao verde (Soeiro \& Castilho, 2016; DorierAprill, 2006), os agentes imobiliários e os consumidores dos novos imóveis têm buscado a proximidade com relação, também, à direção dos ventos na perspectiva de vender mais conforto ambiental.

Daí se chama a atenção para se levar em conta, na gestão urbana, preocupações com relação à preservação e/ou à conservação da natureza na perspectiva, por exemplo, de um urbanismo bioclimático, o qual vem acumulando experiências em outros lugares do mundo.

En este sentido, son muy oportunos los criterios bioclimáticos para el planeamiento general con el objeto de intentar cerrar los ciclos ecológicos de matéria y energía, reducir las huellas ecológicas de los asentamientos, minimizar los impactos negativos sobre el aire, el água y el suelo y, además, usar de un modo eficiente las energías disponibles. [...] facilita[ndo] a los profesionales relacionados con el diseño urbano y la ordenación del territorio una metodología eficaz para que puedan integrar en todas las escalas del planeamiento, los objetivos del desarrollo sostenible y puedan lograr unas ordenaciones residenciales integradas con inteligencia en su entorno, que comporten un menor consumo energético y proporcionen una mayor calidad de vida para sus habitantes (Higueras, 2013, p. 13).

Especificamente sobre o vento, como o ar em movimento, compreendendo este elemento como um dos fatores essenciais para o conforto térmico nos espaços urbanos, Higueras (Ibidem, p. 16) reforça que:

Para conseguir un trazado urbano que responda a las premisas del urbanismo bioclimático es fundamental que se consideren:

1. Una correcta adecuación de la orientación de la red viaria principal por criterios de soleamiento y de viento. 
2. Una adecuación de los espacios urbanos con respecto a la humedad ambiental (favoreciéndola en determinados periodos o no).

Considera-se, então, segundo a autora supra citada, que "Para el proyecto urbanístico es imprescindible conocer los vientos locales a través de los datos de velocidad y orientación, para analizar y evaluar la acción del viento sobre el territorio, conocer su variabilidad y obrar en consecuencias". (Ibidem, p. 91) E isso na medida em que a circulação dos ventos locais dependerá de um conjunto de fatores ambientais: geográficos, topográficos, tipo de vegetação e de solo, bem como das construções humanas.

No caso específico da cidade de Recife, a forte densidade das construções de imóveis verticais, na cidade, principalmente quando realizada no sentido $\mathrm{N}-\mathrm{S}$, isto é, ao longo da zona costeira da cidade (Figura 2), vem cada vez mais formando uma extensa barreira linear à circulação natural dos ventos marítimos. O que, por sua vez, acontece acelerando a situação da expansão dos espaços de ilha de calor, acarretando, sobretudo nas zonas mais centrais da cidade, significativa mudança em termos de temperatura e fluxo de circulação dos referidos ventos.

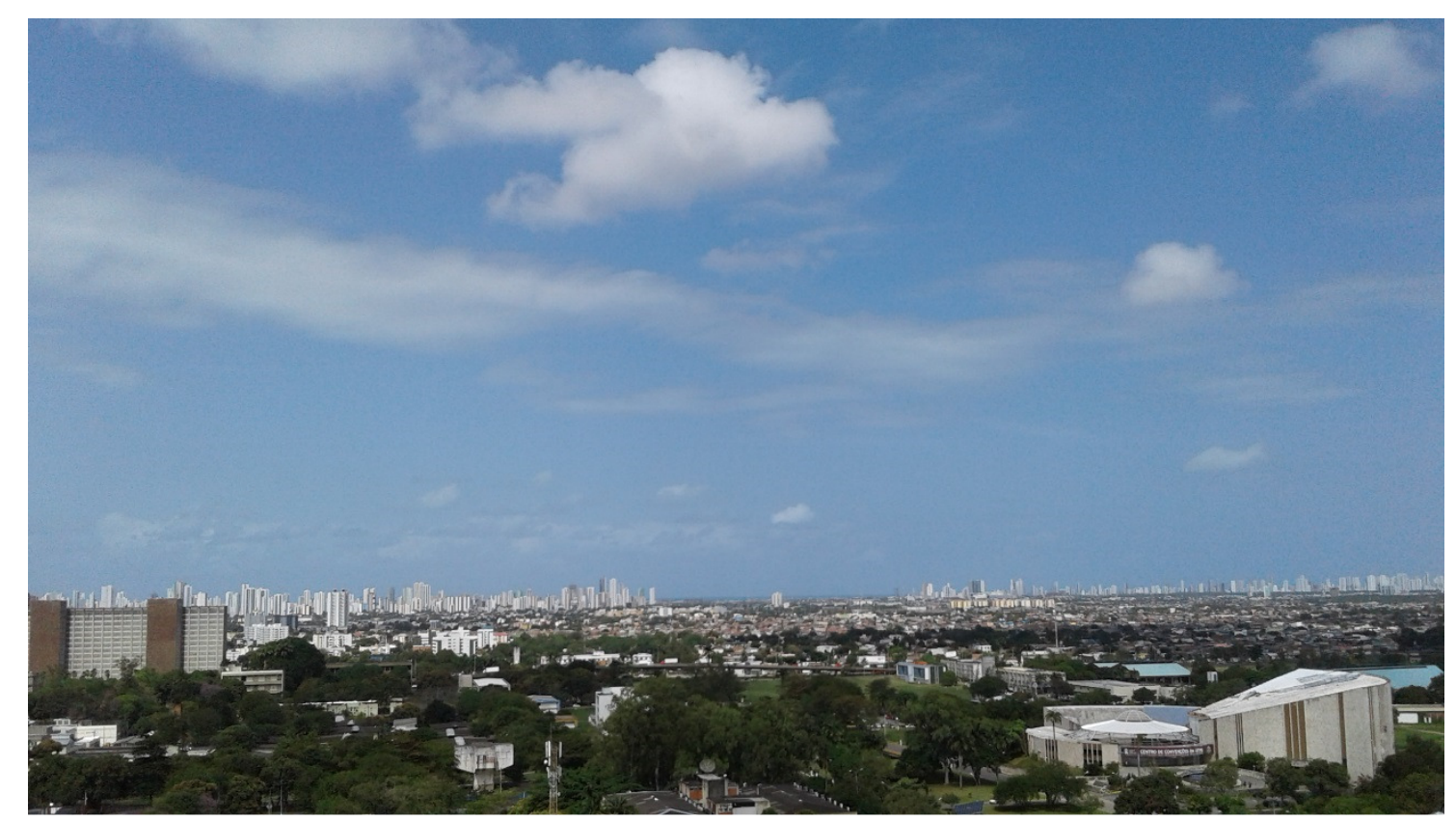

Figura 2. Recife: paredão de construções verticais ao longo da zona costeira. Fonte: imagem do arquivo pessoal do primeiro autor, em 2016.

Ao influir, portanto, na circulação natural dos ventos marítimos tal como está ocorrendo, reduz-se o seu potencial de atenuador da acentuada tropicalidade do clima do Recife, problema que terminou, direta ou indiretamente, tendo tido o apoio do Estado na medida em que esta instituição política da sociedade eximiu-se do seu papel de controlar os rumos do processo de crescimento urbano no município.

É verdade que não se vai mais explodir a cidade existente a fim de fazer retornar à situação anterior. Por outro lado, ainda é possível, pelo menos, controlar o processo de densificação das construções no sentido N-S ou S-N a fim de garantir os corredores através dos quais parte dos ventos em tela ainda consegue circular no sentido L-O, pelo menos mantendo as ainda existentes "janelas urbanas".

Nessa perspectiva, não se deve controlar processos de construção do espaço apenas visando solucionar o problema da saturação dos fluxos do mercado no espaço, mas, ao mesmo tempo, visando promover o conforto ambiental a partir da criação e expansão dos espaços de amenidades para todos os seres humanos, evitando o atual processo de privatização da natureza em curso.

Daí por que, nesta pesquisa, procuramos refletir, ao mesmo tempo, sobre o sentido da apropriação - "privada" - da natureza em ações urbanísticas, na cidade, a partir do uso dos ventos marítimos, indagando sobre quem de fato tem tido a garantia do seu direito aos ventos marítimos, no curso da história urbana em Recife.

\section{Material e Métodos}

Como a realidade ambiental inerente ao processo de construção do espaço urbano e, por conseguinte, dos seus diversos ambientes, é contraditória, conflituosa e complexa no âmbito de uma totalidade em movimento permanente, a 
presente pesquisa está sendo realizada com base no método de abordagem materialista históricodialético sob o paradigma da complexidade, relação transversalizada pela perspectiva ambiental.

Si tratta della coscienza che i fatti ambientali non hanno un valore assoluto, non possono essere studiati oggettivamente in sé e per sé, mentre ricevono sempre un valore entro il sistema di relazioni in cui sono posti. L'analisi geografica dovrà dunque partire da queste relazioni, studiate appunto dall'economia e dalle altre scienze sociali (Dematteis, 1995, p. 52).

Este mesmo autor insistiu na importância de se considerar as condições ambientais ecológicas, históricas e aquelas resultantes dos investimentos públicos - a fim de entender a vocação ambientalista do processo de produção do espaço (regional), bem como as políticas do território e disciplinares. Nessa perspectiva, argumenta o mesmo autor que:

Riconoscere una nuova struttura territoriale, più che scoprire una realtà nuova significa far incontrare fatti che già esistevano senza un nome con una congiuntura storico-politica che, quando ci proponiamo di gestirla, ci induce a nominarli. Il principale vantaggio di questa concezione è di esaltare le potenzialità della geografia come scienza del realmente possibile, riscattandola dalla servile condizione di retorica del falsamente necessario (Ibidem, p. 70).

O materialismo histórico-dialético é uma proposta metodológica de abordagem da realidade social que, compreendendo a construção do espaço urbano como um processo histórico contínuo no tempo e sempre inacabado, considera o conjunto das contradições e dos conflitos como fatores que compõem o mundo como totalidade em permanente totalização em algum sentido. Faz-se necessário, então:

[...] deixar claro ainda que não existe 'a' dialética como se todos os dialéticos formassem um exército com a mesma roupa e as mesmas armas. Este fenômeno seria muito pouco dialético. $\mathrm{Na}$ prática encontramos não só dialéticas diferentes, divergentes, mas até mesmo contraditórias, como em qualquer campo metodológico. Vamos tentar argumentar em favor da dialética histórico-estrutural que nos parece a mais consentânea com a realidade histórica, porque equilibra a contento o jogo das condições objetivas e subjetivas. [...] A história se 'move' por leis necessárias objetivas, mas a par de seu lado objetivo natural, possui o lado subjetivo, político, de conquista humana cultural (Demo, 1995, p. 8889 , destaques do autor).

É justamente neste processo complexo de totalização que se tecem os diversos ambientes da existência humana na cidade, como uma totalidade complexa, razão pela qual definimos aqui o ambiente como a complexidade das inter-relações entre as diversas dimensões da sociedade-natureza: pessoas, economia, política, cultura, ideologia, animais, água, verde, ventos, etc. Desse modo, achamos por bem integrar esta abordagem do materialismo histórico-dialético ao paradigma da complexidade, o qual:

[...] pede para pensarmos nos conceitos, sem nunca dá-los por concluídos, para quebrarmos as esferas fechadas, para restabelecermos as articulações entre o que foi separado, para tentarmos compreender a multidimensionalidade, para pensarmos na singularidade com a localidade, com a temporalidade, para nunca esquecermos as totalidades integradoras. [...] A totalidade é, ao mesmo tempo, verdade e nãoverdade, e a complexidade é isso: a junção de conceitos que lutam entre si (Morin, 2000, p. 192).

Portanto, o problema relativo à redução da função dos ventos marítimos no espaço da cidade de Recife não é algo isolado do contexto histórico do processo de produção do espaço urbano local. Este processo, portanto, tem tudo a ver com a evolução das formas de uso do espaço pela sociedade brasileira no curso da história do seu processo de urbanização, visando ao atendimento de intencionalidades inerentes, principalmente, ao capitalismo.

A principal "contradição" engendrada no processo ora em discussão - o uso privado dos ventos no processo de construção do espaço urbano - reside sobretudo na construção de espaços que se tornam insustentáveis à qualidade de vida na cidade. Contudo, faz-se necessário conceber a contradição como algo relativo, daí porque as aspas, ou seja, para ressaltar a diferença. Neste 
sentido, não obstante a aceitação da dialética, considera-se, ao mesmo tempo, que:

Para liberar a diferença é preciso um pensamento sem contradição, sem dialética, sem negação: um pensamento que diga sim à divergência; um pensamento afirmativo cujo instrumento é a disjunção; um pensamento do múltiplo - da multiplicidade dispersa e nômade que não é limitada e confinada pelas imposições do mesmo... (Foucault, 2013, p. 256).

No que diz respeito às intencionalidades são, por vezes, questionadas por processos de negação e enfrentamento com base nas intencionalidades inerentes às horizontalidades do território urbano, sobretudo em função da percepção das contradições engendradas pela própria dinâmica do capitalismo. Contudo, os conflitos ou as tensões postos em ação pelas pessoas através das suas diversas formas de agir protestos, reivindicações, movimentos sociais, etc. - nem sempre acontecem para substituir um modo de produção por outro, mas para, por meio da conquista de direitos, construir o espaço do cidadão para si.

Em função da complexidade supramencionada, somente se poderá resolver o problema ora identificado pela reflexão através da adoção de posturas interdisciplinares de uso teórico e prático - do espaço, liberando-se de posturas simplistas calcadas na busca do progresso e/ou desenvolvimento. Nesse sentido, vale ressaltar que "complexidade significa que a ideia de progresso [...] comporta incerteza, comporta sua negação e sua degradação potencial, e, ao mesmo tempo, a luta contra essa degradação" (Morin, op. cit., p. 97-98).

Daí por que, simultaneamente, tem-se que buscar a contextualização de tudo que existe na terra, juntando os fragmentos para pensar o Planeta como uma complexidade a ser tratada interdisciplinarmente. Isso porque:

Contextualizar e globalizar são os procedimentos absolutamente normais do espírito e, infelizmente, a partir de um certo nível de especialização, que passa a ser da hiper-especialização, o fechamento e a compartimentação impedem contextualizar e globalizar. Contextualizar é o problema da ecologia. Nenhum ser vivo pode viver sem seu ecossistema, sem seu meio ambiente. Isso quer dizer que não podemos compreender alguma coisa de autônomo, senão compreendendo aquilo de que ele é dependente (Morin, 1999, p. 25, destaque nosso).

Esta escolha metodológica reside, principalmente, no fato de que uma pesquisa não se fecha "no local e no particular", como ainda diz Morin (2014, p. 97) posteriormente ao trabalho anteriormente citado, mas que os concebe em seus respectivos conjuntos, "estaria apta a favorecer o senso da responsabilidade e o da cidadania" com suas consequências "éticas e cívicas".

\section{Resultados}

Tratando-se de uma pesquisa que ainda se acha em seu início, este ensaio traz como resultado preliminar algumas considerações sobre o tema em apreço, o que resultou do trabalho da revisão da literatura realizada até o presente momento.

Desse modo, em seguida, colocar-se-á em destaque alguns dos principais achados concernentes às relações dos ventos - marítimos e "terrais" - com o processo de produção do espaço urbano em Recife.

Nesse sentido, visando, principalmente, refletir sobre a importância climática dos ventos locais em Recife, Andrade (1952) considerou alguns dos efeitos deste elemento climático sobre as condições térmicas do corpo humano em ambientes de forte calor, argumentando que:

Os que habitam esta faixa marítima, tão providencialmente refrescada [...], 'recebem para o prazer do corpo como para o sumo bem da vida e da saúde, brande e benigno leste, provocado pelos ares matutinos, que delicia homens e animais, defendendo-os contra a radiação de um sol a perpendículo'. De 'leste' é a denominação genérica com que o primeiro observador meteorológico em terras do Brasil [...] resume todos os ventos soprando aqui do mar (Ibidem, p. 16-17).

Além desta função dos ventos, este mesmo autor havia também destacado, ao mesmo tempo, sua relevância como fator saneador nos ambientes urbanos construídos na cidade de Recife. Isso aconteceu, notadamente, ao ter chamado a nossa atenção para o fato de que:

A luta sanitária do Recife - de resto a luta comum a todas as aglomerações humanas progressivas, mas, entre nós, revestindo por vezes um caráter de peculiar gravidade, em virtude de especiais condições topográficas, de clima, de costumes e circunstâncias 
outras correlatas; a luta sanitária do Recife foi constantemente a porfia, no suceder dos anos cada vez mais difícil, pela eliminação dos seus próprios resíduos. Já por si mesmas as aglomerações urbanas multiplicam os ensejos de contaminação. 'Não apenas diretamente [...] pela elevação da densidade microbiana, como também pela criação duma ambiência particularmente favorável'. [...] O Recife fedeu horrivelmente, centúria após centúria, sobretudo no século passado [XIX]. Acumulando dentro de si mesmo seus resíduos... (Andrade, 1952, p. 33-34).

Tendo em vista o imediatamente acima citado, o autor não negligenciou a relevância dos ventos marítimos na dispersão dos ventos terrais, ou seja, daqueles contaminados por esse ambiente pleno de micróbios.

Desse modo, na perspectiva de refletir sobre o conforto ambiental em Recife, os ventos foram destacados, ainda, como elemento de dispersão e, mesmo, de eliminação da densidade dos resíduos engendrados, por outro lado, por uma lógica de crescimento urbano criadora e reforçadora dos miasmas.

Com efeito, os miasmas constituíam um problema muito grave sobretudo antes da difusão do que conhecemos hoje em termos de perspectivas sanitaristas de produção dos espaços urbanos, capazes de contribuir para tecer ambientes saudáveis à vida humana.

Em suma, o vento conduz consigo o clima de onde vem, salvo se 'substancialmente', modificado no trajeto. E, sem precisarmos, talvez, de reiterar essa evidência, salientemos como, graças ao nosso alísio de Sudeste, aqui, nestas latitudes baixas do Recife, vem até nós, com ele, o clima mais ameno das latitudes médias, oceânicas, do hemisfério austral (Ibidem, p. 54).

Em outra perspectiva, também não se negligenciou o papel dos ventos como atenuador das "ilhas de calor" na cidade, defendendo a necessidade da manutenção de um equilíbrio saudável entre natureza e sociedade. Isso na busca de contribuir para a revisão do modelo vigente de construção das cidades, e isto no sentido da expansão de "espaços de amenidades". A este respeito, vale a pena ressaltar que:

Mercê dessas circunstâncias, os calores desconfortáveis, na maioria dos lugares e na maior parte do ano, tornam-se uma questão de diferença entre bairros, entre dois lados da mesma rua [o voltado para o nascente e o voltado para o poente] ou entre horas do dia [as da manhã e as da tarde]. Acresce que, ao longo da orla litorânea, a exposição mais direta aos ventos, impedindo que se sinta verdadeiro calor em qualquer hora e em qualquer época, constitui um dos fatores mais importantes da preferência, por parte de parcela cada vez maior da população, pela faixa marinha como área residencial. Área que se estende linearmente, em sua parte urbanizada (Melo, 1978, p. 3940).

Considerando os princípios dialéticos de totalidade, contradição e conflito, enquanto a urbanização se expandia cada vez mais, sobretudo a partir de meados do século XIX, desrespeitando a circulação natural dos ventos, mas, ao mesmo tempo, usando esteticamente a natureza, verifica-se que parte significativa da natureza foi de certo modo suprimida.

Como consequência nítida deste processo de construção da cidade, muitos dos seus espaços tornaram-se desconfortáveis no que tange o morar, principalmente em termos do aumento paulatino do calor, pelo aumento da temperatura (Figuras 3 e 4), criando, ampliando e consolidando a situação de ilha de calor. Desse modo, este problema não se deve a uma "vingança da natureza" como se tem dito popularmente, mas a uma reação da natureza em função dos sistemas de ações humanos, mormente quando se calcam na lógica técnicoinstrumental capitalista, a qual nega completamente os movimentos da natureza para fazer valer, mormente, a geração de valores econômicos.

A série de mapas da Figura 3 demonstra, segundo o autor (Ibidem, p. 83), que os maiores valores em vermelho, com intervalos superiores a $31^{\circ} \mathrm{C}$, localizados expressivamente em 2006, contribuíram para configurar um arquipélago de calor na área urbana, ao passo que, em verde e amarelo, acham-se representadas as unidades de conservação e os corpos hídricos, apresentando intervalos inferiores a $27^{\circ} \mathrm{C}$.

A série de mapas da Figura 4 demonstra, segundo o autor (Ibidem, p. 100), que as áreas em vermelho são as de predominância de coberturas impermeáveis e com elevado adensamento urbano, apresentando os maiores valores de fluxo de calor no solo local, suscitando a ideia da consolidação de ilhas de calor na cidade. Desse modo, será que se não se tivesse expandido a barreira dos altos 
edifícios de apartamentos ao longo da costa, desde os anos 1970, quando observado por Melo (1978), haveria tal situação?

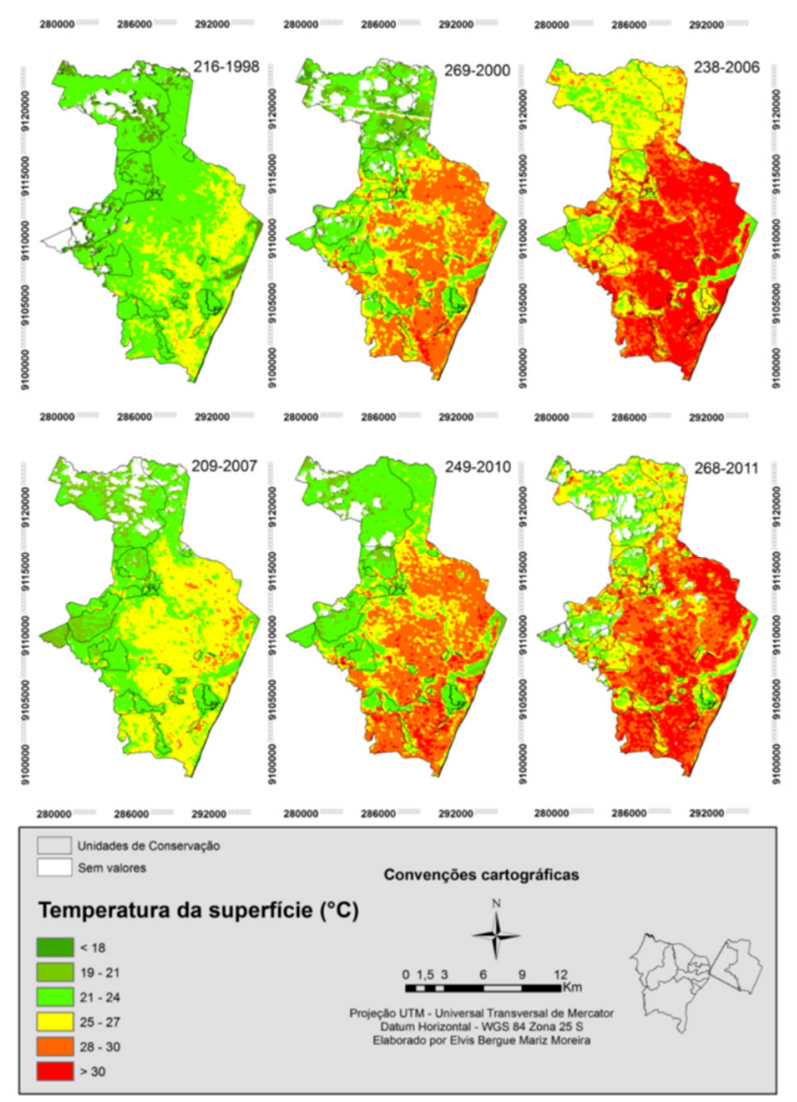

Figura 3. Carta temática da distribuição espacial das temperaturas da superfície nas datas 1998, 2000, 2006, 2007, 2010 e 2011. Fonte: Imagem extraída da tese de doutorado de Moreira (2014), cedida pelo coordenador do Grupo de Pesquisa Tropoclima do Departamento de Ciências Geográficas da UFPE.

Como metas mais significativas pensadas na presente pesquisa, almeja-se, assim, continuar dando visibilidade a um problema - o do uso da natureza no espaço, pela consideração do caso dos ventos marítimos - que geralmente as pessoas não enxergam de imediato. Isto é de fundamental importância para a retomada da qualidade de vida nos espaços vividos. Deste ponto de vista, pode-se começar a construir as possibilidades para o repensar a lógica de construção do espaço urbano vigente, no sentido de superá-la e/ou, pelo menos, de redirecioná-la.

Outra meta desta pesquisa refere-se à necessidade de destacar a relevância da posição das pessoas frente aos ventos marítimos, como um dos fatores fundamentais à promoção da qualidade de vida na cidade, expandindo os espaços de amenidades e eliminando os de ilha de calor. Isso na perspectiva do resgate do conjunto das condições mais saudáveis à promoção da tão almejada sustentabilidade no urbano.

Uma outra meta, mas não de menor relevância, consiste na contribuição que a pesquisa poderá levar para a necessária revisão das políticas públicas urbanísticas de cunho ambiental na cidade, incentivando a necessidade da utilização de posturas interdisciplinares - de pensar e implementar ações no espaço - a fim de, partindo de uma perspectiva bioclimática de urbanismo, melhor compreender e agir na complexidade do problema ora ressaltado.

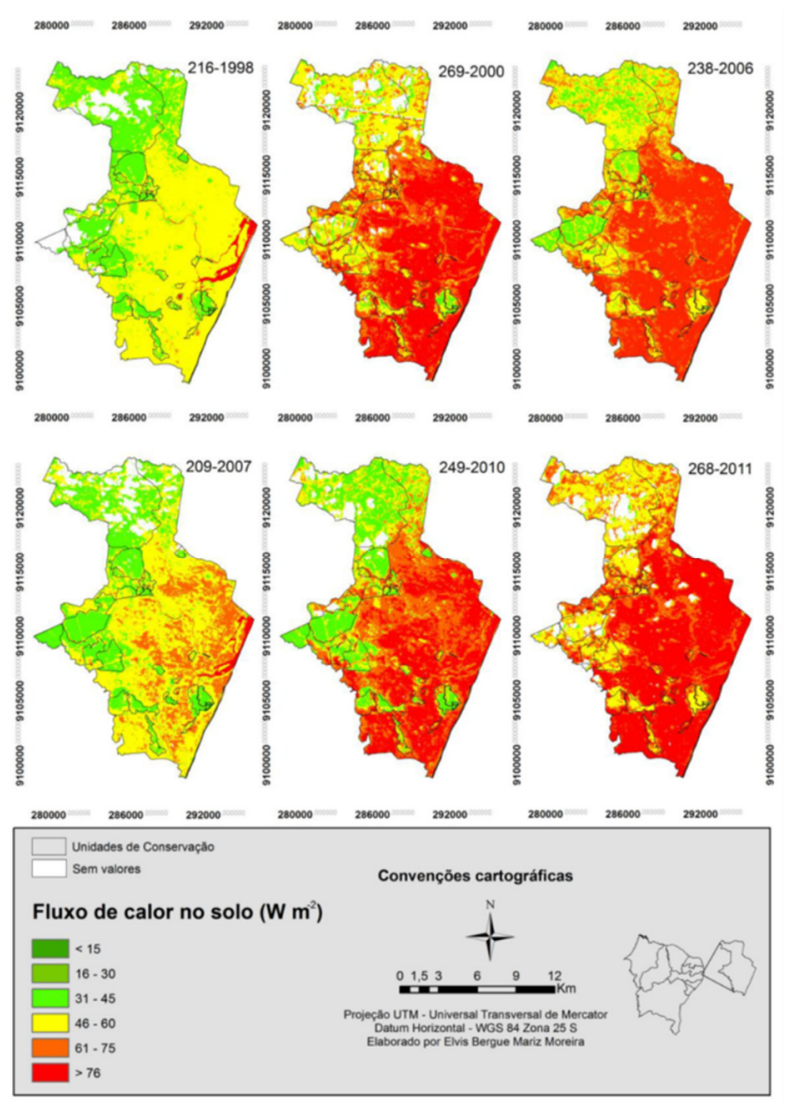

Figura 4. Carta temática da distribuição espacial do fluxo de calor no solo nas datas 1998, 2000, 2006, 2007, 2010 e 2011. Fonte: Imagem extraída da tese de doutorado de Moreira (2014), cedida pelo coordenador do Grupo de Pesquisa Tropoclima do Departamento de Ciências Geográficas da UFPE.

$\mathrm{O}$ pensamento acerca do direito à natureza no campo e na cidade não é algo novo na história da ciência (geografia), uma vez que, desde principalmente meados do século XIX, o geógrafo anarquista Élisée Reclus - através do seu Do sentimento da natureza nas sociedades modernas havia chamado a nossa atenção para a necessidade do Homem rever as ações e práticas de destruição da natureza, visando a criação de novas ações e práticas, desta vez recuperadoras da beleza das paisagens. 
Foi justamente a partir de meados do século XIX que se começou a acelerar o processo de destruição da natureza, o que teve continuidade até os nossos dias a despeito da existência de leis que poderiam protege-la. Recife presenciara, também naquele período, o início da negação e mesmo supressão das águas e do verde, bem como da criação a partir de meados do século XX, de barreiras à "natural" circulação dos ventos marítimos pelo espaço urbano, em favor do crescimento sem limites (Castilho, 2014). Hoje em dia, tem-se algo mais substancial no que se refere ao entendimento e à garantia da natureza como direito social, o que se reforça com:

[...] uma preocupação na superação da utilização da natureza como um processo de satisfação individual, vinculado ao consumismo [da 'propaganda verde'], através da construção de um processo de ação e uso da natureza como uma forma de emancipação coletiva, constituindo no mundo contemporâneo, um direito à natureza na cidade para todos os seus habitantes (Henrique, 2009, p. 14).

$\mathrm{O}$ urbanismo - conjunto de ações que acontecem na cidade, implementadas pelos principais agentes construtores do espaço - deve prestar bem atenção para esta questão, na medida em que se tratam de ações que, em sua complexidade, constituem os principais instrumentos com os quais os agentes públicos $\mathrm{e}$ privados organizam os seus espaços, tecendo, enfim, os diversos ambientes nos quais as pessoas têm que viver, trabalhar, brincar, etc.

Isso acontece no contexto em que os espaços vividos, segundo Frémont (1999), são progressivamente alienados a fim de obedecer aos imperativos da racionalidade técnico-instrumental capitalista, hoje, neoliberal, a qual, possui como propósito transformar o espaço em mercadoria a fim de acelerar o processo de geração de valores. Mesmo que ocorrendo à revelia dos princípios legais socialmente construídos no país. A este respeito:

Art. 225. Todos têm o direito ao meio ambiente ecologicamente equilibrado, bem de uso comum do povo e essencial à sadia qualidade de vida, impondo-se ao Poder Público e à coletividade o dever de defende-lo e preservá-lo para as presentes e futuras gerações.

$\S 1^{\circ}$ Para assegurar a efetividade desse direito, incumbe ao Poder Público:

I - preservar e restaurar os processos ecológicos essenciais e prover $\mathrm{o}$ manejo ecológico das espécies e ecossistemas; [...]

IV - exigir, na forma da lei, para instalação de obra e atividade potencialmente causadora de significativa degradação do meio ambiente, estudo prévio de impacto ambiental, a que se dará publicidade; [...].

$\S 3^{\circ}$ As condutas e atividades consideradas lesivas ao meio ambiente sujeitarão os infratores, pessoas físicas ou jurídicas, a sanções penais e administrativas, independentemente da obrigação de reparar os danos causados... (Brasil, 1988).

Respeitando tais princípios constitucionais, alguns dos quais devidamente regulamentados, poderíamos ter ambientes efetivamente diferente do atual. Ademais, tem-se que levar em conta o princípio da natureza, tal como sugerido por Louv (2014), pelo qual, em seus processos de implementação, as ações urbanísticas devem também superar a cultura do institucionalismo transcendental, ou seja,

"[...] também temos de pensar em como as instituições devem ser criadas aqui e agora, para promover a justiça reforçando as liberdades negativas e substantivas, bem como o bem-estar das pessoas que vivem hoje e que amanhã terão partido" (Sen, 2011, p. 111).

Nesta perspectiva, liberando-se do seu caráter higienizador-gentrificador, as ações urbanísticas, como políticas públicas capazes de promover o desenvolvimento do estado de Pernambuco, deveriam ser efetivamente públicas. Para isso, necessita-se que seus projetos se reaproximem cada vez mais das pessoas e dos seus ambientes de existência, exercendo o permanente diálogo com seu povo de maneira a contemplar o que tem origem nas diversas territorialidades da cidade. $\mathrm{O}$ que, se demandado por movimentos sociais fortes, seguramente, acontecerá. Para o que, segundo o mesmo autor, os direitos humanos, tal como o direito a estar próximo e/ou na passagem dos ventos marítimos, podem servir como inspiração.

A proximidade dos ventos marítimos como direito de todos pode também ser pensada e praticada de maneira a se conquistar o conforto ambiental para todos na cidade, na medida em que promove espaços de amenidades contra os de ilha de calor os quais, pela própria tendência da expansão urbana sem limites e controle, tende a 
crescer. Isso porque, como se resgatou no início deste ensaio, tal elemento da natureza - os ventos marítimos - também constitui um atenuador fundamental da acentuada tropicalidade em Recife.

\section{Considerações finais}

Acreditamos que a reaproximação entre sociedade e natureza é de fundamental importância para o desenvolvimento territorial com sustentabilidade no estado de Pernambuco (cujos governos têm fomentado programas de investimentos em pesquisas e tecnologias voltados para o desenvolvimento do estado), assim como em todo o território nacional.

O tema objeto deste ensaio destacou a relevância da consideração da natureza como mais um fator importante no conjunto das dimensões capazes de promover o propalado desenvolvimento. Isso porque, o cuidado e a consideração para com a preservação - não somente a conservação - dos elementos da natureza na cidade não somente contribuem para promover, em seu conjunto, o desenvolvimento social como, concomitantemente, o desenvolvimento econômico no espaço de vida das pessoas, respeitando a diversidade ambiental existente em cada lugar.

No que diz respeito, ainda, à sua relevância para o desenvolvimento territorial com sustentabilidade, reiteramos, portanto, a necessidade da garantia do direito à natureza para todos e todas na cidade propiciando conforto ambiental, o que acontece em diversos lugares do mundo em que o contato com jardins, parques e águas propicia sensação de bem-estar nas pessoas (Louv, 2014; Henrique, 2009).

No caso ora tratado, a posição das pessoas com relação à direção dos ventos marítimos em lugares de acentuado calor, também pode ser considerado como mais outro elemento importante - além do contato com o verde e as águas - nesse sentimento de bem-estar na perspectiva do bem viver na cidade.

Por sua vez, em se sentindo bem, porque vivendo em situação de conforto ambiental, as pessoas podem ficar ainda mais dispostas do que já o são para continuarem criando e inovando também no âmbito da economia, elevando sua capacidade produtiva. Mas está claro que esta produtividade não pode ser isolada da perspectiva da concretização da qualidade de vida, justiça social e, consequentemente, satisfação das pessoas na sua vida cotidiana

Ademais, espaços urbanos bem cuidados e organizados, apresentando equilíbrio no que tange à aproximação entre espaço construído (urbanizado) e natureza constituem fatores importantes à promoção do desenvolvimento de uma série de atividades econômicas na cidade, a exemplo daquelas que dão suporte ao lazer e ao turismo. O que, decerto, contribui para incrementar a economia local ao engendrar diversas oportunidades de negócios e empregos.

\section{Agradecimentos}

Agradecemos ao Conselho Nacional de Desenvolvimento Científico e Tecnológico $(\mathrm{CNPq})$, pela Bolsa de Produtividade, nível 1, concedida ao Professor Cláudio Jorge Moura de Castilho; bem como à Fundação de Amparo à Ciência e Tecnologia de Pernambuco (FACEPE), pela Bolsa de Iniciação Científica concedida ao estudante Arthur Felipe de Melo Teixeira.

\section{Referências}

ANDRADE, G. O. de. 1952. Ares e ventos do Recife. Recife: Faculdade de Filosofia de Pernambuco.

AURÉLIO, M. 2012. Meditações. São Paulo: Martin Claret.

BRASIL. 1988. Constituição da República Federativa do Brasil. Brasília: Editora Mandarino.

CASTILHO, C. J. M. de. 2014. Água e espaço urbano em Recife. Interesses sociais e geopolítica interna. Revista Brasileira de Geografia Física, v.7, n.3, p.597-614.

CASTRO, J. de. 1964. Homens e caranguejos. São Paulo: Brasiliense.

CRIEKINGEN, M. V. 2006. A cidade revive! Formas, políticas e impactos da revitalização residencial em Bruxelas. In: BIDOUZACHARIASEN, C. De volta à cidade. Dos processos de gentrificação às políticas de "revitalização" dos centros urbanos. São Paulo: Annablume, pp.89-120.

DEMATTEIS, G. 1995. Progetto implicito. Il contributo della geografia umana alle scienze del territorio. Milano: Franco Angeli.

DEMO, P. 1995. Metodologia científica em ciências sociais. São Paulo: Atlas.

DORIER-APRIL, E. (org.) 2006. Ville et environnement. Paris: Sedes.

FOUCAULT, M. 2013. Arquelogia das ciencias e história dos sistemas de pensamento. $3^{\mathrm{a}}$ ed. Rio de 
Janeiro: Forense Universitária. (coleção ditos \& escritos).

FRÉMONT, A. 1999. La région espace vécu. Paris: Flammarion.

HENRIQUE, W. 2009. O direito à natureza na cidade. Salvador: Edufba.

HIGUERAS, E. 2013. Urbanismo bioclimático. Madrid: Editorial Gustavo Gili.

LINS, R. C. 1982. Alguns aspectos originais do sítio urbano do Recife. In: ANDRADE, M. C. de. (org.). Capítulos de geografia do Nordeste. Recife: União Geográfica Internacional - Comissão do Brasil, pp.81-85.

LOUV, R. 2014. O princípio da natureza. Reconectando-se ao meio ambiente na era digital. São Paulo: Cultrix.

MELO, M. L. de. 1978. Metropolização e subdesenvolvimento. O caso do Recife. Recife: Editora da Universidade Federal de Pernambuco.

MOREIRA, E. B. M. 2014. Balanço de energia e evapotranspiração na cidade do Recife-PE por sensoriamento remoto. Tese de doutorado, Universidade Federal de Pernambuco. Recife, Pernambuco, Brasil. 158p.

MORIN, E. 1999. Por uma reforma do pensamento. In: PENA-VEGA, A.; ALMEIDA, E. P. de. (org.) O pensar complexo: Edgard Morin e a crise da modernidade. Rio de Janeiro: Garamond.

2000. Ciência com consciência. Rio de Janeiro: Bertrand Brasil. 2014. A cabeça bem-feita: repensar a reforma, reformar o pensamento. $21^{\mathrm{a}}$ ed. Rio de Janeiro: Bertrand Brasil.

RECLUS, E. 2010. Do sentimento da natureza nas sociedades modernas. São Paulo: Expressão \& Arte: Editora Imaginário.

SEN, A. 2011. A ideia de justiça. São Paulo: Companhia das Letras.

SOEIRO, I. C. de M.; CASTILHO, C. J. M. de. 2015. O caráter ideológico da natureza e o processo de produção do espaço em Tejipió/Recife. Revista Brasileira de Geografia Física, v.8, n.1, p.221-235. 